\title{
Interfacial molecular interactions of cellobiohydrolase Cel7A and its variants on cellulose
}

\author{
Akshata R. Mudinoor ${ }^{1} \mathbb{D}$, Peter M. Goodwin² ${ }^{\mathbb{B}}$, Raghavendra U. Rao ${ }^{3}$, Nardrapee Karuna ${ }^{1,4}$, Alex Hitomi ${ }^{1}$, \\ Jennifer Nill ${ }^{5,6}$ and Tina Jeoh ${ }^{1 *}$ (1)
}

\begin{abstract}
Background: Molecular-scale mechanisms of the enzymatic breakdown of cellulosic biomass into fermentable sugars are still poorly understood, with a need for independent measurements of enzyme kinetic parameters. We measured binding times of cellobiohydrolase Trichoderma reesei Cel7A (Cel7A) on celluloses using wild-type Cel7A $\left(W T_{\text {intact }}\right)$, the catalytically deficient mutant Cel7A E212Q (E212Q $\left.\mathrm{Q}_{\text {intact }}\right)$ and their proteolytically isolated catalytic domains (CD) (WT core and $E 212 \mathrm{Q}_{\text {core, }}$ respectively). The binding time distributions were obtained from time-resolved, super-resolution images of fluorescently labeled enzymes on cellulose obtained with total internal reflection fluorescence microscopy.
\end{abstract}

Results: Binding of $\mathrm{WT}_{\text {intact }}$ and $\mathrm{E}^{2} 12 \mathrm{Q}_{\text {intact }}$ on the recalcitrant algal cellulose (AC) showed two bound populations: $\sim 85 \%$ bound with shorter residence times of $<15 \mathrm{~s}$ while $\sim 15 \%$ were effectively immobilized. The similarity between binding times of the WT and E212Q suggests that the single point mutation in the enzyme active site does not affect the thermodynamics of binding of this enzyme. The isolated catalytic domains, $\mathrm{WT}_{\text {core }}$ and $\mathrm{E}^{2} 12 \mathrm{Q}_{\text {core, }}$ exhibited three binding populations on AC: 75\% bound with short residence times of 15 s (similar to the intact enzymes), $20 \%$ bound for $<100$ s and $\sim 5 \%$ that were effectively immobilized.

Conclusions: Cel7A binding to cellulose is driven by the interactions between the catalytic domain and cellulose. The cellulose-binding module (CBM) and linker increase the affinity of Cel7A to cellulose likely by facilitating recognition and complexation at the substrate interface. The increased affinity of Cel7A to cellulose by the CBM and linker comes at the cost of increasing the population of immobilized enzyme on cellulose. The residence time (or inversely the dissociation rates) of Cel7A on cellulose is not catalysis limited.

Keywords: Trichoderma reesei Cel7A, Super-resolution, Single-molecule imaging, Catalytic domain, Binding lifetime, Dissociation rate, Heterogeneous interfacial enzyme kinetics

\section{Background}

The population of the world is projected to exceed 9 billion by the year 2050 , leading to $50 \%$ more demand for petroleum based liquid fuels that currently power the

${ }^{*}$ Correspondence: tjeoh@ucdavis.edu

${ }^{1}$ Biological and Agricultural Engineering, University of California, Davis, One Shields Ave., Davis, CA 95616, USA

Full list of author information is available at the end of the article transportation sector [1]. Biofuels derived primarily from the most abundant biopolymer cellulose are a promising substitute for fossil fuels due to lowered greenhouse gas emissions, reduced climate change and health costs associated with their use [2]. However, the process of releasing soluble sugars from cellulose, a major component of the plant cell wall matrix is challenging. Cellulose, crystalline assemblies of $\beta-1,4$ linked glucose, is a very 
recalcitrant material and therein lies the challenge to the use of this substrate on a commercial scale [3].

Industrial cellulosic biofuel production processes employ fungal cellulase mixtures to breakdown cellulose into soluble sugars for further fermentation into fuels. In fungal cellulase mixtures, cellobiohydrolases (e.g., Cel7A of the well-characterized Trichoderma reesei) are the molecular workhorses that hydrolyze the recalcitrant cellulose in synergy with supporting endocellulase and oxidative activities $[4,5]$. The processive hydrolysis of cellulose by $T$. reesei Cel7A (Cel7A) entails multiple sequential steps: adsorption of the enzyme to the cellulose surface, surface diffusion, complexation wherein the catalytic domain recognizes and engages the reducing end of a single molecule of cellulose within its active site tunnel, glycosidic bond hydrolysis to form cellobiose as the product, product expulsion from the active site and subsequent sliding along the molecule to release several consecutive cellobioses (processive hydrolysis), decomplexation and finally desorption from the cellulose surface [6]. Mechanistic kinetic models of cellulose hydrolysis suggest that the complexation and decomplexation steps are rate-limiting elementary cellulase-cellulose interactions and that cellulose hydrolysis rates are largely insensitive to the catalytic rate constant of the complexed enzymes [6].

The multi-modular structure of Cel7A, a $45-56 \mathrm{kDa}$ catalytic domain $(\mathrm{CD})$ and a $\sim 4 \mathrm{kDa}$ carbohydratebinding module (CBM) connected by a $\sim 10-15 \mathrm{kDa}$ glycosylated linker, gives rise to multiple binding configurations of this enzyme on cellulose $[7,8]$ as all three domains have been shown to have affinity to cellulose [9-11]. Cel7A that is actively hydrolyzing cellulose must be complexed to cellulose by its $\mathrm{CD}$; however, complexed Cel7A can stall and thereby become inactive [12, 13]. The different populations of bound Cel7A are challenging to distinguish in biochemical determinations of interaction rate parameters that are typically obtained from fitting hydrolysis or binding time courses, thereby resulting in broad ranges of values [14]. In one example, a dissociation rate constant of Cel7A (' $k_{\text {off }}$ ') from crystalline and amorphous cellulose was estimated from hydrolysis curves to be $0.01-0.02 \mathrm{~s}^{-1}$ [15]. While another study measuring rates of insoluble reducing end formation reported Cel7A $k_{\text {off }}=0.0032 \mathrm{~s}^{-1}$ on bacterial microcrystalline cellulose and $0.007 \mathrm{~s}^{-1}$ on amorphous cellulose [16].

Single-molecule imaging is a means to directly measure desorption rates of cellobiohydrolases from cellulose [17-19]. Total internal reflection fluorescence microscopy (TIRFM) enables visualization of individual fluorescently labeled cellulases that approach within $\sim 100 \mathrm{~nm}$ of the evanescent wave excited imaging surface. When isolated cellulose fibrils are deposited on the imaging surface, individual cellulases that bind to the fibril surfaces can be visualized [17]. A typical single-molecule imaging experiment records 'movies' consisting of multiple consecutive images over time. Analysis of the residence times of the cellulases observed to appear (bind) and disappear (unbind) from view (the cellulose surface) in the movie provides a measure of average binding lifetimes of the cellulases on cellulose (or 'desorption rates' from reciprocals of the binding times). This method has been used to determine various binding modes and desorption rates of Cel7A [17, 19] and Cel6A [18]. Despite similar enzymes, substrates and experimental setups, published studies of Cel7A report desorption rates that differ by $1-2$ orders of magnitude.

In this study, we used super-resolution single-molecule imaging to measure the binding lifetimes of wildtype Cel7A purified from a commercial T. reesei enzyme mixture $\left(\mathrm{WT}_{\text {intact }}\right)$ and the catalytically deficient mutant $\left(\mathrm{E} 212 \mathrm{Q}_{\text {intact }}\right)$ expressed in T. reesei on crystalline cellulose fibrils. A point mutation of the nucleophile Glu 212 to Gln 212 reduces the catalytic efficiency of Cel7A enzyme 2000 -fold [20, 21] and provides a structurally intact Cel7A mutant to examine how catalysis impacts enzymebinding lifetimes. Proteolytically isolated catalytic domains ( $\mathrm{WT}_{\text {core }}$ and $\mathrm{E} 212 \mathrm{Q}_{\text {core }}$ ) were also used to investigate binding specificity and lifetimes in the absence of the linker and binding modules. Unique to this study was the development of a robust and automated image analysis method to obtain binding lifetimes of all enzymes observed in the movies [22].

\section{Results}

\section{Cellulose fibrils on the imaging surfaces}

The cellulose used in this study was a never-dried, highly crystalline algal cellulose (AC) isolated from cell walls of C. aegagropila and "polished" with a concentrated acid treatment. The polishing step reduced the productive Cel7A binding capacity (i.e., the number of Cel7 A complexation sites per mass of cellulose) to $0.83 \pm 0.13 \mu \mathrm{mol} / \mathrm{g}$, which is considerably lower than either non-polished AC or other commercially available celluloses [13, 23]. Single-molecule binding experiments using non-polished AC and phosphoric acid swollen cellulose (PASC) suffered from heavily congested fibril surfaces where it was difficult to track individual molecules even when diminishingly low enzyme concentrations were used [24] (Additional file 1: S3 and S5). Acid polished AC (from here on referred to only as 'AC') significantly alleviated congestion of enzymes on the fibril surfaces (e.g., Fig. 1b).

Individual and aggregated fibrils settled in random orientations on the surface of hydrophobically silanized glass (Fig. 2). Individual fibrils were tens of microns 
long and as thin as $\sim 3-6 \mathrm{~nm}$. Larger bundles, $>10 \mathrm{~nm}$ in height, were also common (e.g., Fig. 2b). Figure 2a exemplifies typical coverage of fibrils in a $50 \times 50 \mu \mathrm{m}^{2}$ area, a size comparable to the field of view obtained from TIRFM imaging in our setup. The white circle in (Fig. 2a) highlights particles $(\sim 30-40 \mathrm{~nm}$ high $)$ commonly observed on the surfaces. While the composition of the particles is unknown, high phase contrasts from these particles in the AFM phase images suggest that these particles are more viscoelastic (i.e., 'softer') than the cellulose fibrils. One possibility is that these are nano-air bubbles trapped at the hydrophobized glass surface.

\section{Specificity of Cel7A to cellulose is determined by the carbohydrate-binding module (CBM)}

$\mathrm{WT}_{\text {intact }}$ and $\mathrm{E} 212 \mathrm{Q}_{\text {intact }}$ bound preferentially to cellulose rather than to the hydrophobic glass substrate (background), as visualized by colocalization of the emission from pontamine fast scarlet 4B (PFS) stained cellulose fibrils (Fig. 3b, h) and fluorescence from Cy5-labeled cellulases (Fig. 3a, g) in the overlays (Fig. 3c, i). In contrast, overlays of the corresponding core enzymes and the PFSstained cellulose showed an abundance of spots bound to the background (Fig. $3 \mathrm{~d}-\mathrm{f}, \mathrm{j}-\mathrm{l}$ ), indicating that the proteolytically isolated $\mathrm{WT}_{\text {core }}$ and $\mathrm{E}^{212 \mathrm{Q}_{\text {core }}}$ had less targeted binding to cellulose. Moreover, even in the absence of PFS, Cel7A and E212Q (WT intact and E212Q $\mathrm{Q}_{\text {intact, }}$ respectively) concentrated immediately and specifically to cellulose such that traces of the fibrils were easily identifiable from binding patterns of the fluorescently labeled enzymes in each frame (e.g., Fig. 1b and Additional file 2). For CBM-less core versions of these enzymes $\left(\mathrm{WT}_{\text {core }}\right.$ and $\left.\mathrm{E} 212 \mathrm{Q}_{\text {core }}\right)$, fibrils were less apparent despite a tenfold increase in enzyme loading, and in some cases only identifiable when all 2500 frames of images were summed (e.g., Fig. 4d, e, j, k). The non-specificity of CD binding to cellulose has been reported previously and attributed to the lack of the carbohydrate-binding domain implicated in targeting cellulases to the cellulose surface [25]. Here, we observe that Cel7A without the linker and CBM bind readily and abundantly to the hydrophobic glass surface despite passivation with BSA. Similar results were obtained when PASC was used as the cellulose substrate, shown in Additional file 1: S6.

\section{Cel7A and Cel7A E212Q exhibit short and long residence times on cellulose}

The interaction of $\mathrm{WT}_{\text {intact }}$ with cellulose fibrils appeared relatively stationary, with many enzymes residing on the cellulose fibrils for long periods (Additional file 2). Some enzymes bound and unbound during the window of observation; in areas that do not appear to have fibrils, enzymes appeared and disappeared rapidly. $\mathrm{WT}_{\text {core }}$ coverage on the imaging surfaces was more distributed and more dynamic than $\mathrm{WT}_{\text {intact }}$ (Additional files 3, 4, 5). There were some $\mathrm{WT}_{\text {core }}$ enzymes that remained for long durations on the surface, but it was less clear if these are bound to cellulose because they did not obviously align as if on a fibril. It is possible that some of these distributed enzymes are bound to the nanoparticles on the surfaces (Fig. 2a). E212Q $\mathrm{Q}_{\text {intact }}$ binding to cellulose appeared largely stationary (Additional files 6 and 7), while $\mathrm{E} 212 \mathrm{Q}_{\text {core }}$ at the imaging surface were more spatially distributed and dynamic than $\mathrm{E} 212 \mathrm{Q}_{\text {intact }}$ (Additional files 8 and 9). In
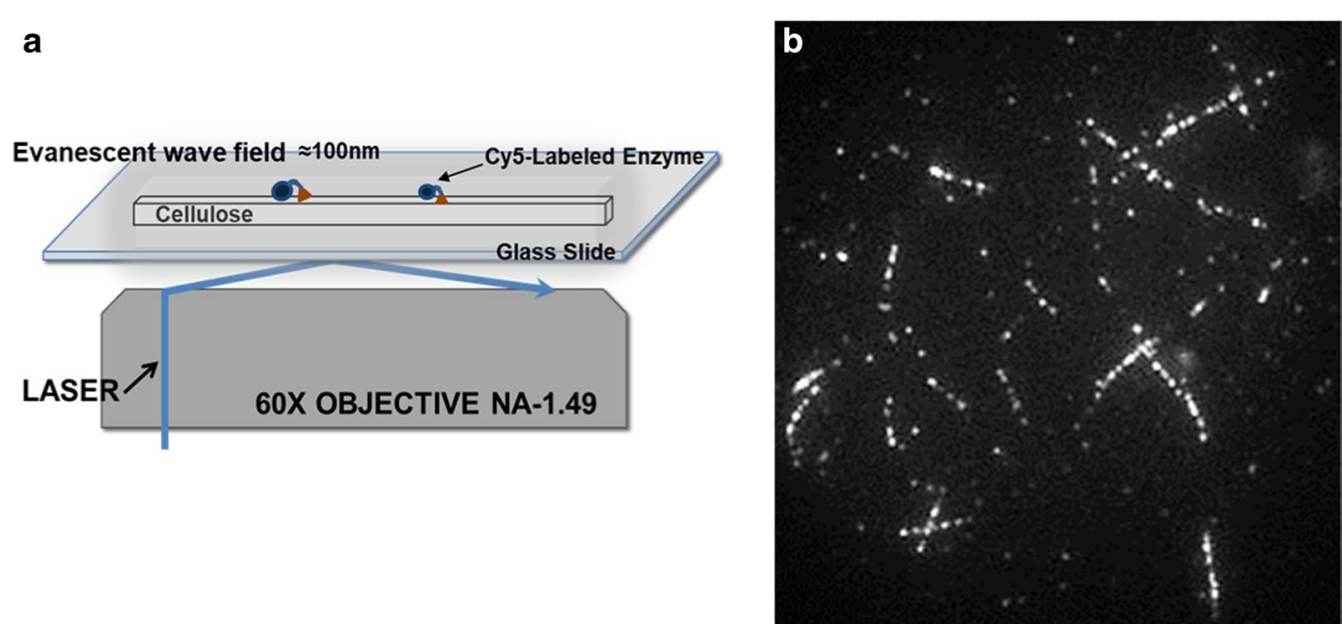

Fig. 1 a A schematic illustration (not drawn to scale) of the through-objective TIRFM setup used to image Cy5-labeled enzymes bound to a cellulose fibril under evanescent wave excitation extending $\sim 100 \mathrm{~nm}$ above the glass/water interface. $\mathbf{b}$ Cellulose fibrils with surface-bound Cy5-labeled cellulases were easily identifiable in the Cy5 fluorescence channel $\left(56 \times 56 \mu^{2}\right.$ field of view). Spots correspond to individual Cel7A enzymes. A single frame (1 s) of a 2500-frame data set is shown in $\mathbf{b}$ 

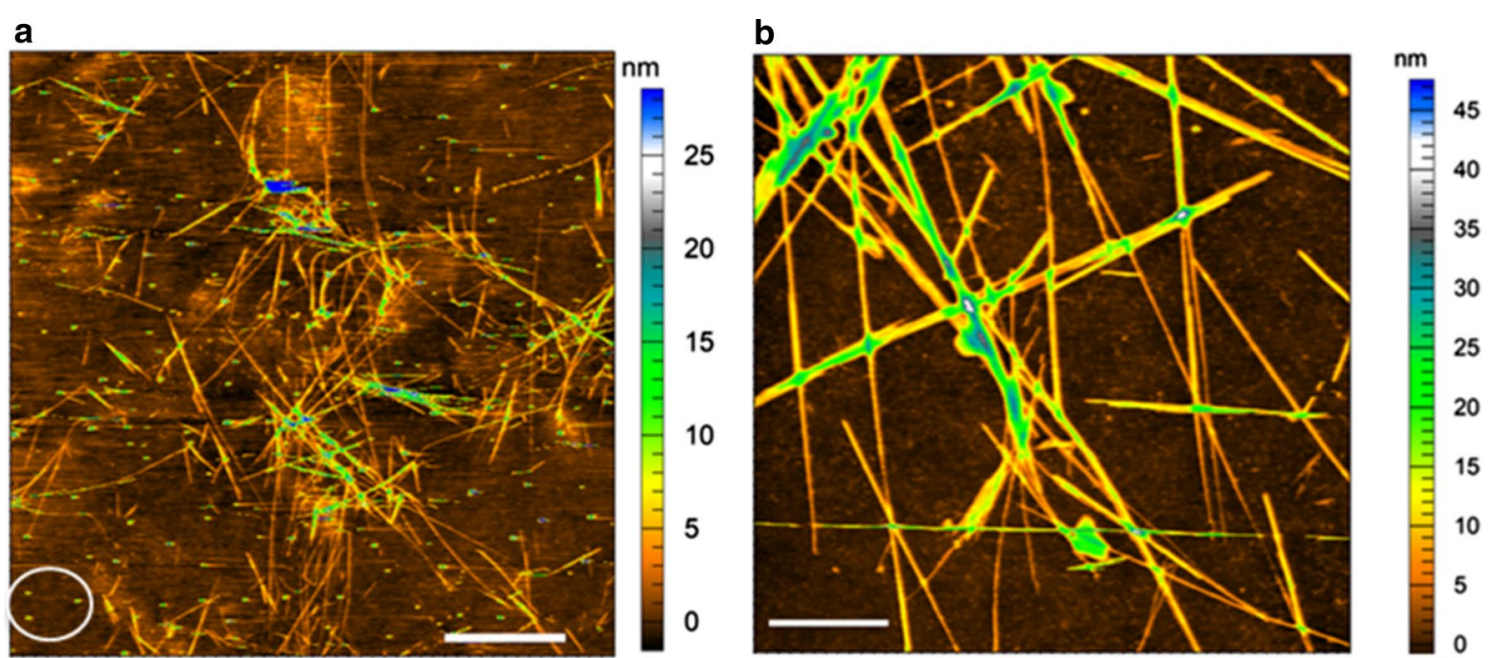

Fig. 2 Atomic force microscopy (AFM) images of algal cellulose gravity-deposited on hydrophobically silanized glass imaging surfaces. a $50 \times 50 \mu \mathrm{m}^{2}$ field of view (scale bar $=10 \mu \mathrm{m}$ ), and $\mathbf{b} 5 \times 5 \mu \mathrm{m}^{2}$ field of view (scale bar $=1 \mu \mathrm{m}$ ). White circle in $\mathbf{a}$ highlights particles seen on the surface. Individual fibril heights ranged from $\sim 3$ to $6 \mathrm{~nm}$

general, cellulose fibrils were easily traced in experiments with $\mathrm{WT}_{\text {intact }}$ (Additional file 2) and $\mathrm{E}^{212 \mathrm{Q}_{\text {intact }}}$ (Additional files 6 and 7) as the fluorescently labeled enzymes bound along the length of the fibrils. In contrast, because of the sparser binding of $\mathrm{WT}_{\text {core }}$ (Additional files 3,4 and 5) and $\mathrm{E} 212 \mathrm{Q}_{\text {core }}$ (Additional files 8 and 9), enzyme loading had to be increased to be able to trace the cellulose fibrils.

Super-resolution reconstructions of the raw image sequences pinpointed the locations of the bound enzymes, allowing us to determine the residence times of each enzyme bound to cellulose. Separating the superresolution summed images (i.e., a combined image of all collected frames) into three binding time ranges $(<10 \mathrm{~s}$, $11-200 \mathrm{~s}, 201-2500 \mathrm{~s}$ ) revealed a general tendency of all four Cel7A variants to have short residence times $(<10 \mathrm{~s})$ on the background and longer residence times on cellulose fibrils (Fig. 5). Again, even though the hydrophobized glass surfaces were treated with BSA prior to the addition of the enzymes in the imaging channels, Figs. 3 and 5 indicate that the passivation did not necessarily prevent enzyme binding to the background. However, in Fig. 5 we see that the enzymes do not accumulate on the background; the enzymes touch down on the surface, but leave shortly thereafter. The traces of the fibrils are increasingly pronounced with longer residence time ranges, indicating that enzymes that bind to cellulose tend to remain bound longer than $10 \mathrm{~s}$.

To determine characteristic binding times of Cel7A on cellulose, the binding times of the enzymes that bound and unbound from cellulose fibrils during the observation window were compiled into histograms. The binding time histograms of the Cel7A variants were best fit by two- or three-exponential decays, indicating 2-3 populations differing in characteristic binding times interacting with cellulose (Fig. 6). Most of the enzymes bound to cellulose (75-85\%) had short residence times of 14-15 s (Population 1 in Fig. 6a, b). Similar analysis of binding to the background (where no cellulose was present) also indicated short residence times by the majority $(\sim 90 \%)$ of the enzymes (Fig. 6a, b), which is consistent with our observations in Fig. 5d, h, l, p. The characteristic residence time of Population 1 Cel7A on the fibrils (14-15 s), however, was longer than on the background $(\sim 10 \mathrm{~s})$, indicating an enhanced affinity of this enzyme to cellulose. Moreover, this enhanced affinity to cellulose relative to hydrophobized glass is not attributable to the CBM as the core versions of the enzymes behaved similarly.

As expected from the trends in Fig. 5, Cel7A enzymes bound for prolonged durations on cellulose. $\mathrm{WT}_{\text {intact }}$ appeared to have extended binding times of $187 \mathrm{~s}$ (Population 2) and $1260 \mathrm{~s}$ (Population 3) (Fig. 6a, c). However, these times reflect the photobleaching times of the Cy5 dye of $195 \mathrm{~s}$ and $1100 \mathrm{~s}$ (Additional file 1: S2). Thus, the analysis of $\mathrm{WT}_{\text {intact }}$ residence times on cellulose was subject to photo-physical limitations of the Cy5 label; i.e., $\sim 20 \%$ of the $\mathrm{WT}_{\text {intact }}$ were effectively immobilized on the cellulose fibrils. Therefore, rather than 3 populations, we can only consider 2 bound populations of $\mathrm{WT}_{\text {intact }}$ bound to cellulose-a short-lived, but majority (81\%) population of $15 \mathrm{~s}$, and a minority (19\%) population that is immobilized. Binding analysis of $\mathrm{E} 212 \mathrm{Q}_{\text {intact }}$ also suggests a long-lived population (Population 2) bound to cellulose (Fig. 6c) for longer than the characteristic time for 


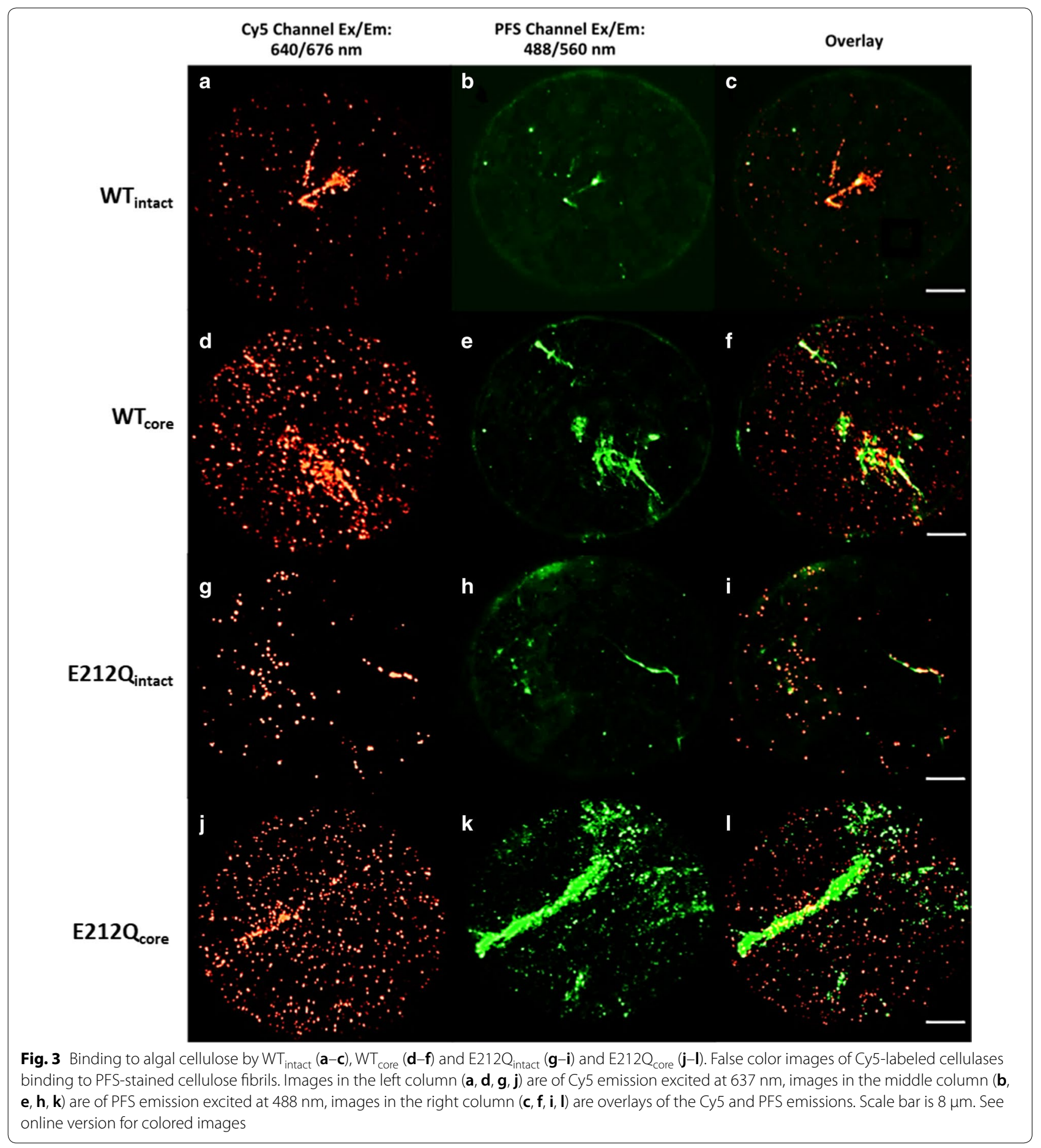

the Cy5 dye to photobleach. In the case of $\mathrm{E} 212 \mathrm{Q}_{\text {intact }}$, the long-lived component was not resolved into two populations because of a lower number of enzymes included in the analysis. Nevertheless, we see that $15 \%$ of this enzyme was effectively immobilized on cellulose.
The core versions of Cel7A and E212Q, without linker and CBM, exhibited a population with prolonged binding to cellulose not truncated by photobleaching of the Cy 5 dye (Fig. 6c); binding times of population 2 of $\mathrm{WT}_{\text {core }}$ and $\mathrm{E} 212 \mathrm{Q}_{\text {core }}$ were $99 \pm 12 \mathrm{~s}$ and $104 \pm 10 \mathrm{~s}$, respectively. 


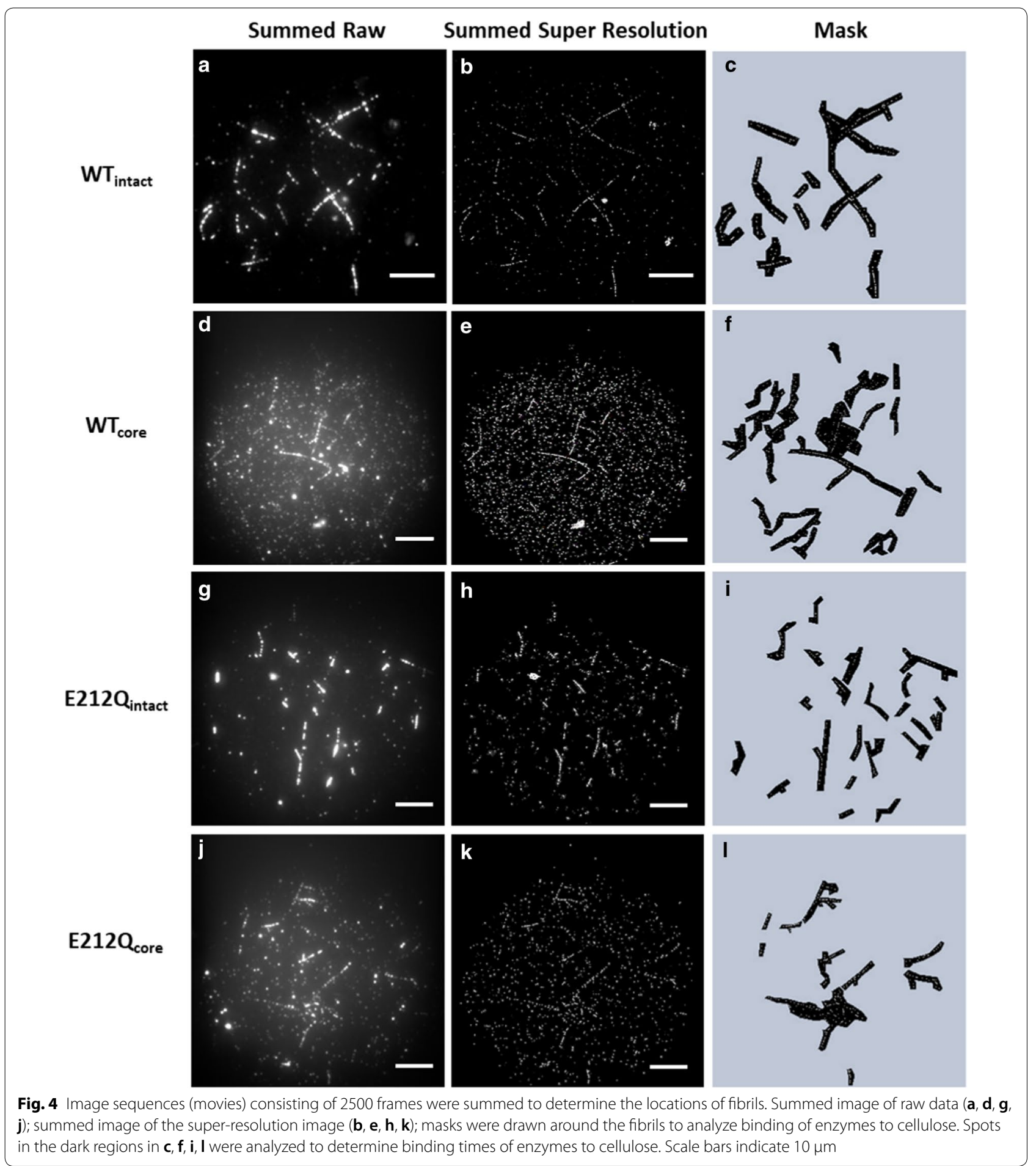

Both enzymes also appeared to have a small fraction $(6-7 \%)$ that bound for $>200 \mathrm{~s}$ (Population 3). Taken together, of the population of $\mathrm{WT}_{\text {core }}$ and $\mathrm{E} 212 \mathrm{Q}_{\text {core- }}$ that bound for extended durations, $\sim 75 \%$ released within $\sim 100 \mathrm{~s}$ while $\sim 25 \%$ remained immobilized. This was in contrast to the intact enzymes where $100 \%$ of the bound enzyme with extended binding times appeared to be immobilized. 


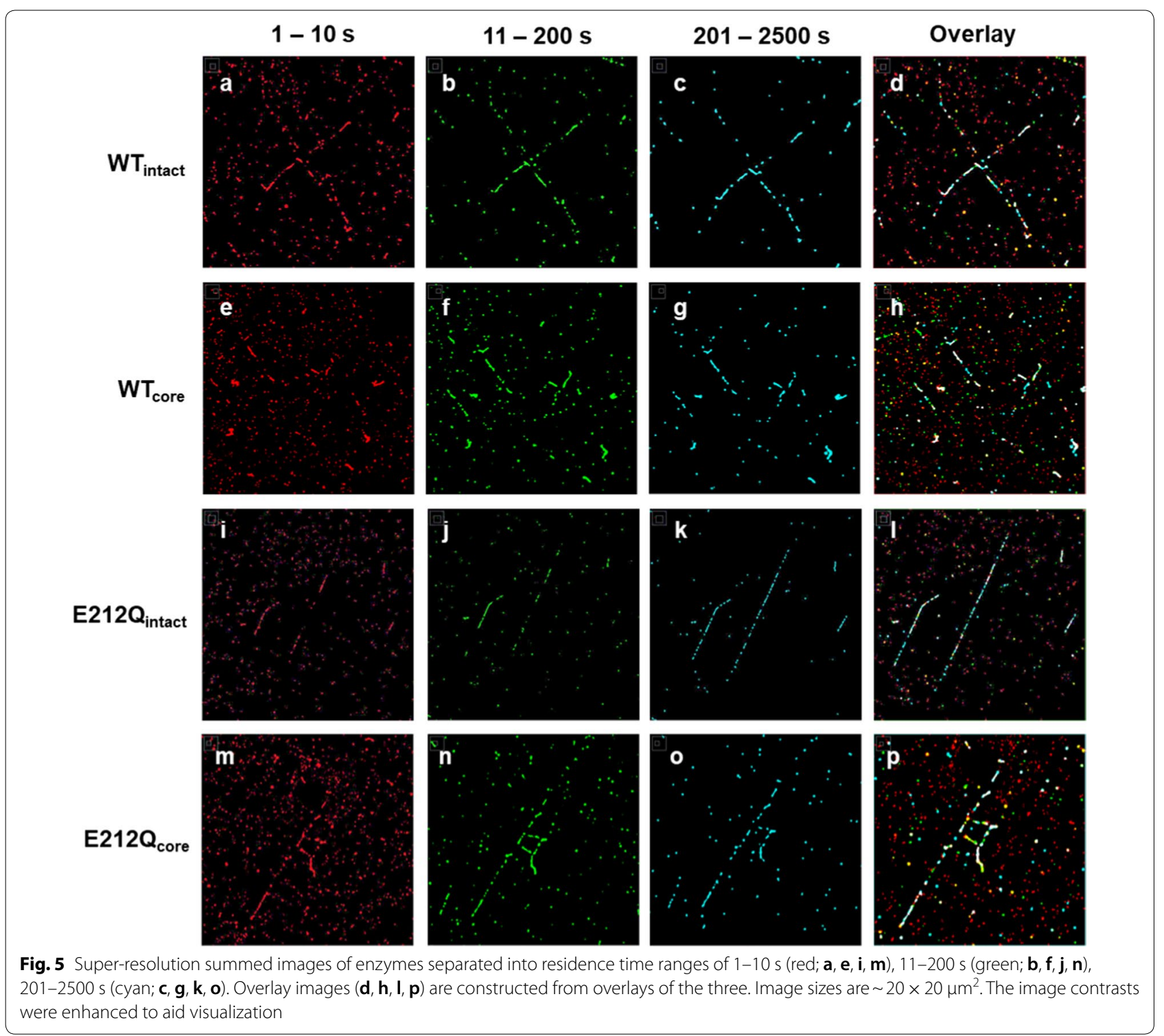

\section{Discussion}

\section{Immobilized Cel7A on cellulose}

All the Cel7A variants exhibited a small, but significant cellulose-bound population with binding times exceeding the limit of photostability of the Cy5 fluorophore (Figs. 6, 7). In our hands, even with the oxygen-scavenging buffer and further decreases in laser intensity to extend fluorophore lifetimes, we were unable to determine the upper limit of the binding times. Additionally, in all the data sets, there were always several enzymes $(\sim 0.1-5 \%)$ that were bound from the first to the last frame (Additional files $2,3,4,5,6,7,8,9)$ [26]. In a data set of 2500 frames, the binding durations of those enzymes exceeded $41.7 \mathrm{~min}$. Hence, we have come to refer to these longlived enzymes on cellulose as 'immobilized' enzymes.
Taking the photostability of the Cy5 dye into account, distinct binding behaviors differentiating the intact Cel7A enzymes ( $\mathrm{WT}_{\text {intact }}$ and $\left.\mathrm{E}^{2} 12 \mathrm{Q}_{\text {intact }}\right)$ and the truncated catalytic domains of these enzymes ( $\mathrm{WT}_{\text {core }}$ and E212Q $Q_{\text {core }}$ ) emerge (Fig. 7). Intact Cel7A exhibited two types of binding-short-lived ( $<15 \mathrm{~s}$ ) and 'immobilized', while the cores exhibited three types of binding-shortlived $(<15 \mathrm{~s})$, extended binding $(\sim 100 \mathrm{~s})$ and immobilized. We speculate that these immobilized Cel7A are those that are complexed but inactive (i.e., not carrying out hydrolysis) at the cellulose interface.

The interaction of Cel7A with cellulose can be parsed into the following elementary steps-adsorption/desorption, complexation/decomplexation and hydrolysis [6]. Correspondingly, the binding sites available for 

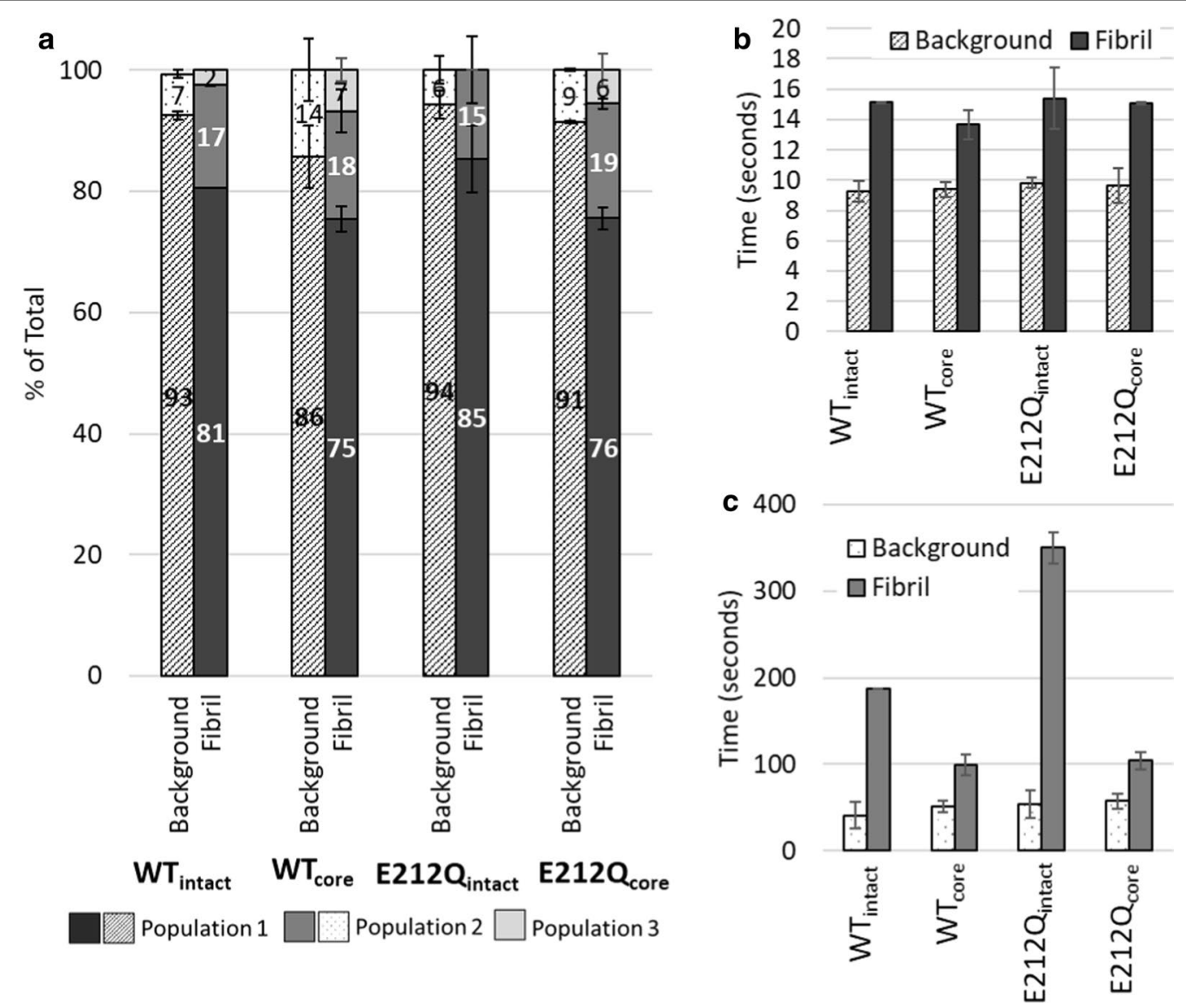

Fig. 6 a Partitioning of Cel7A variants bound to the background and on the cellulose fibrils in 2-3 populations with distinct characteristic residence times; $\mathbf{b}$ characteristic residence times of Population 1 on the background and on the fibrils; $\mathbf{c}$ characteristic residence times of Population 2 on the background and on the fibrils. Characteristic residence times of Population 3 on the cellulose fibrils for $W T_{\text {intact, }}, W_{\text {core, }}$ and E212 $\mathrm{Q}_{\text {core }}$ were $1260 \mathrm{~s}, 389 \pm 44 \mathrm{~s}$, and $645 \pm 225 \mathrm{~s}$, respectively. Error bars represent standard deviations from three independent data sets or the spread between parameter estimates from two independent data sets. Fitting parameters for all data sets are provided in Table S2 of Additional file 1

Cel7A at the substrate interface are complexation sites and adsorption sites (Fig. 8). Complexation sites are those at which Cel7A can fully engage with a cellodextrin within its active site. A complexed Cel7A actively hydrolyzing cellulose is considered to be a productively bound Cel7A (i.e., producing product) [23]. A complexed Cel7A that is not actively hydrolyzing cellulose is non-productively bound. Thus, as illustrated in Fig. 8, Cel7A bound to a complexation site can be either productive or non-productively bound, depending on whether it is actively hydrolyzing cellulose. Adsorption sites are sites at which Cel7A bind to cellulose without engaging its catalytic domain (e.g., binding only by the CBM).

We recently demonstrated that the productive cellulase binding capacity, i.e., the number of productive binding sites per mass of cellulose (moles/g) limits hydrolysis rates of cellulose [14, 23]. Nill and Jeoh [13] further found that during cellulose hydrolysis by purified Cel7A, a fraction of the productive binding sites on cellulose become unavailable due to complexed but inactive (i.e., non-productively bound) Cel7A that persist on the substrate. The algal cellulose used in the current study had an initial productive binding capacity of $0.83 \mu \mathrm{mol} / \mathrm{g}$. While the extent to which Cel7A blocks productive binding sites appears to be cellulose source dependent, we found that at an enzyme loading of $5 \mu \mathrm{mol} / \mathrm{g}$ at $50{ }^{\circ} \mathrm{C}$, $\mathrm{WT}_{\text {intact }}$ blocked $25 \pm 5 \%$ of the productive binding sites on this cellulose. The immobilized fractions of $\mathrm{WT}_{\text {intact }}$ and $\mathrm{E} 212 \mathrm{Q}_{\text {intact }}$ observed in the TIRFM experiments were $19 \%$ and $15 \%$ of the bound enzymes, respectively.

The evidence for a fraction of blocked productive binding sites on cellulose and the evidence for an immobilized fraction of bound enzymes on cellulose together provide a case for an obstructive tendency of Cel7A at the cellulose interface. Nill and Jeoh [13] demonstrated that obstruction of the productive binding sites by irreversibly bound Cel7A contributes to the premature decrease 

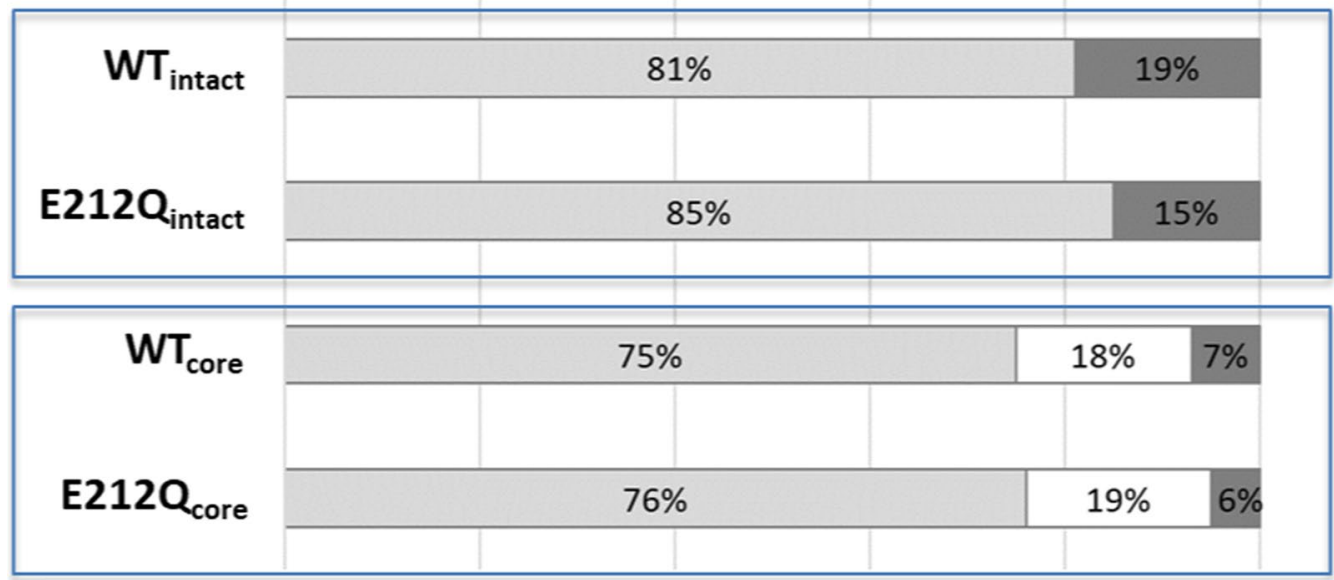

$\square$ Short Binding ( 15s) $\square$ Extended Binding ( 100s) $\quad \square$ "Immobilized"

Fig. 7 The majority $(>80 \%)$ of intact Cel7A (WT intact- or $E 212 Q_{\text {intact }}$ ) exhibited short binding lifetimes on cellulose fibrils, with $<20 \%$ appearing to be effectively 'immobilized'. A large fraction ( 75\%) of the Cel7A catalytic domains (WT core and $\mathrm{E}^{2} 12 \mathrm{Q}_{\text {core }}$ ) also exhibited short binding lifetimes. Approximately $20 \%$ of the core enzyme bound for $~ 100$ s, with only 6-7\% 'immobilized'

of overall hydrolysis rates. Our data comparing WT and E212Q show that Cel7A's tendency to become immobilized at the cellulose interface does not depend on the enzyme's ability to hydrolyze cellulose. Rather, the extensive binding interactions in the active site tunnel of Cel7A dictate binding times [27-29]. Why Cel7A becomes immobilized on the cellulose surface is still unclear and some have speculated that surface 'obstacles' limit processivity and prevent desorption [16]. Further, the question remains if this phenomenon is a consequence of the absence of accessory enzymes such as endoglucanases and lytic polysaccharide monooxygenases (LPMOs) typically co-expressed and synergistic with Cel7A.

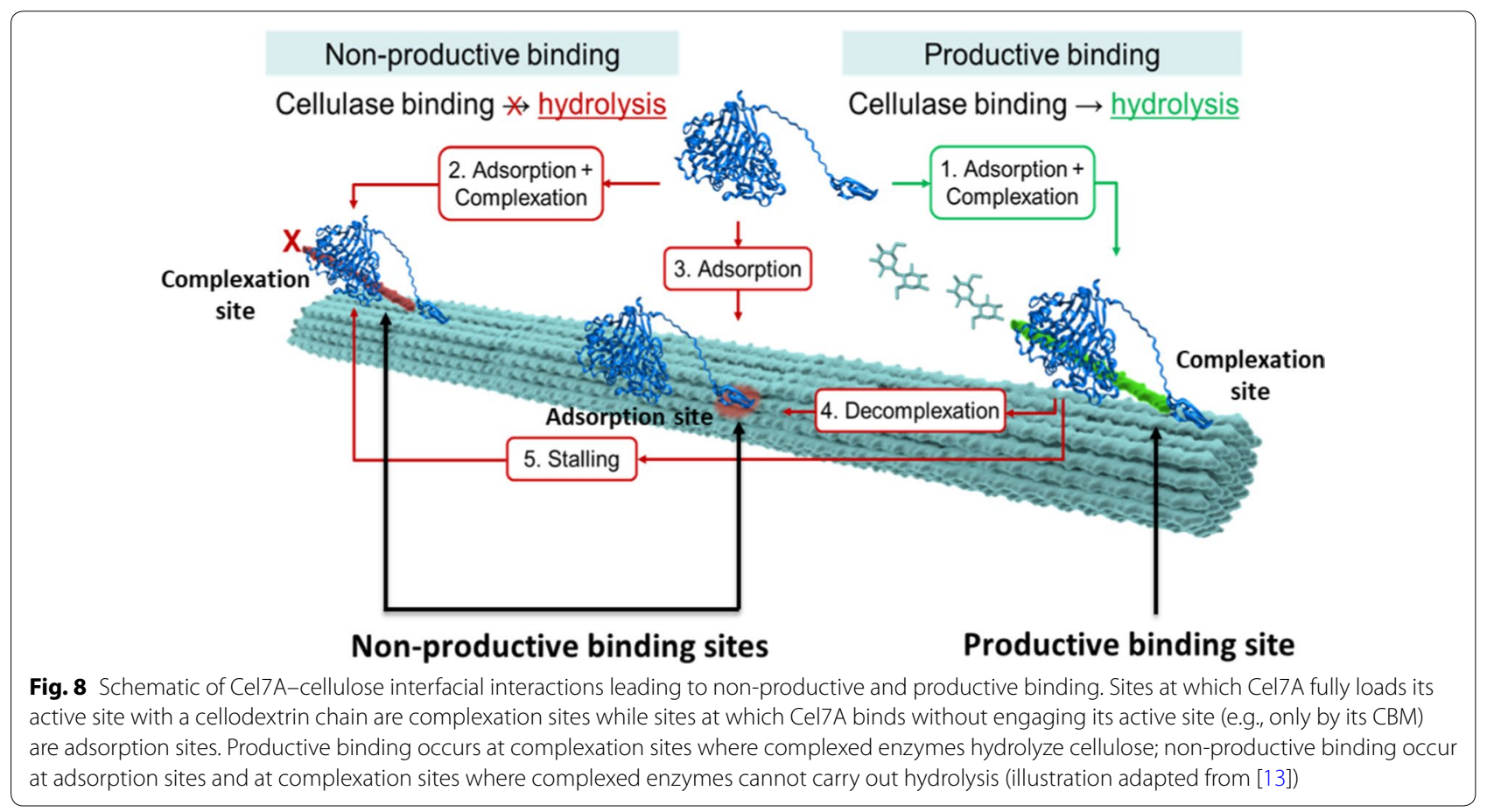




\section{Catalytic domains have lowered affinity and find fewer complexation sites on cellulose}

Without the $\mathrm{CBM}$ and linker, $\mathrm{WT}_{\text {core }}$ and $\mathrm{E}_{212 \mathrm{Q}_{\text {core }}}$ exhibited reduced specificity to cellulose, reduced residence times and reduced size of the immobilized fraction on cellulose fibrils. The CBM of Cel7 A has long been shown to increase the affinity of the enzyme to cellulose [21] and recently calculated to contribute $-5.4 \mathrm{~kJ} / \mathrm{mol}$ to the standard free energy of Cel7A binding to cellulose [29]. The glycosylated linker joining the CBM and the CD of Cel7A has also been shown to have affinity to cellulose [10]. Further, studies suggest that the linker of Cel7A is optimized such that modifications of length or glycosylation on the linker peptide generally decreased the affinity of Cel7A to cellulose [30]. Thus clearly, the CBM and linker have the overall impact of increasing Cel7A's affinity for cellulose.

We additionally observed sparser coverage of $\mathrm{WT}_{\text {core }}$ and $\mathrm{E} 212 \mathrm{Q}_{\text {core }}$ on the cellulose fibrils (Additional files 3, $4,5,8,9)[26]$. Although the explanation may simply be that the reduced affinity from the lack of CBM results in reduced cellulose fibril coverage by the enzymes, the similarity in the short-lived binding time of $\sim 15 \mathrm{~s}$ for the majority population of all the Cel7A variants (with and without CBM) suggests otherwise. Several studies have demonstrated biochemically that the isolated catalytic domain of Cel7A accesses fewer productive binding sites on cellulose [31-33]. Further, the CBM and linker have been shown to participate in the recognition and complexation of the enzyme to cellulose [34, 35]. Thus a more refined explanation for sparser coverage of $\mathrm{WT}_{\text {core }}$ and $\mathrm{E} 212 \mathrm{Q}_{\text {core }}$ on cellulose is that without the CBM and linker, Cel7A recognizes and complexes to fewer sites on cellulose.

The fact that the intact enzymes had a larger immobilized fraction than the cores, and that the cores had a population with extended but shortened binding times imply that the CBM and linker contribute to the immobilization of Cel7A on cellulose. While the catalytic domain of Cel7A find fewer complexation sites on cellulose, productively bound Cel7ACD in fact have higher specific activity on cellulose $[29,36]$. In interfacial kinetics such as that of cellulose hydrolysis, there is an optimum interplay between substrate affinity and specific activity to maximize overall activity of Cel7A [36]. Westh and coworkers describe the activity of intact Cel7 A as desorption-limited and that of the Cel7A catalytic domain as adsorption-limited. In other words, the advantage in finding and complexing to sites on cellulose conferred by the CBM can come at a cost of preventing/slowing dissociation even after the enzyme is no longer actively hydrolyzing; conversely the absence of CBM reduces opportunities to hydrolyze cellulose but also does not prolong unproductive binding of Cel7A.

How long do catalytically active Cel7 A spend on cellulose? The original motivation for this study was to visualize processive Cel7A on cellulose fibrils and to answer the question of how long catalytically active Cel7A enzymes remain bound to cellulose. The single-molecule experiments track the time spent by every enzyme in each field of view from the time it first appears to the time it desorbs and disappears from the surface. The appearance of the enzyme in the field of view indicates that, at a minimum, it has adsorbed to the surface. During the time that this enzyme is observed in the image sequence, it could undergo complexation, hydrolysis, decomplexation, and desorption from the surface of cellulose. Moreover, as illustrated in Fig. 8, binding duration can also include time spent complexed but inactive. Unfortunately, the current experimental setup cannot distinguish between productively and non-productively bound enzymes.

What we did find are the two binding populations of Cel7A on cellulose-one where most spend $15 \mathrm{~s}$ or less and another that is effectively immobilized. Nill and Jeoh [13] found that the immobilized Cel7A on cellulose were not productively bound; however, they also speculated that these are complexed Cel7A that were initially productive but became stalled and non-productive without decomplexing. A popular hypothesis speculates that processive hydrolysis of Cel7A can become stalled by physical obstructions on the surface of the substrate, but the residence time of complexed Cel7A is determined by the thermodynamics of the interactions between the catalytic site residues and the complexed cellodextrin [29]. Simply stated, residence times of complexed Cel7A are expected to be longer than the time during which they are actively hydrolyzing cellulose.

If the short-lived Cel7A population on cellulose were active throughout its binding time, potential supporting evidence is unidirectional movements of Cel7A along the surface of cellulose fibrils due to processive hydrolysis. The intrinsic processivity of Cel7A actively hydrolyzing cellulose can be estimated as a ratio of its turnover number and dissociation rate constant [16]. The turnover number, or catalytic rate constant $\left(\mathrm{k}_{\mathrm{cat}}\right)$, and the dissociation rate constant of $T$. reesei Cel7A, have been reported in the ranges of $2-11 \mathrm{~s}^{-1}$ and $0.14-0.0007 \mathrm{~s}^{-1}$, respectively [14]. The characteristic residence time of the short-lived bound Cel7 A population of $15 \mathrm{~s}$ corresponds to a dissociation rate of $0.067 \mathrm{~s}^{-1}$, well within the range of the previously reported rates. Using the definition above, the intrinsic processivity of the short-lived Cel7A on cellulose in these experiments could range between $\sim 30$ 
and 165 turnovers. Cel7A has been reported to processively hydrolyze cellulose for $\sim 15-90$ consecutive catalytic cycles each time it binds productively to cellulose [14]. Experimentally determined processivities have been viewed as being truncated with respect to the intrinsic processivity of Cel7A and strongly substrate dependent. Interestingly, our estimated intrinsic processivity falls in the general range of the experimental values. Given that each turnover moves the enzyme $\sim 1 \mathrm{~nm}$ [37], the short-lived bound population of Cel7A could translate $~ 30-165 \mathrm{~nm}$ per hydrolytic run. Most of the bound enzymes in the raw data do not appear to translate (Additional files $2,3,4,5,6,7,8,9)$ [26], which may simply be due to a lateral resolution of $220 \mathrm{~nm} /$ pixel. Even with super-resolution localization of the centroids of each spot in the image sequences, detection of unambiguous sliding movements of enzymes was exceedingly difficult. There were occasional observations of enzyme movements (e.g., Additional file 10), but these events were rare. The raw data sets with accompanying super-resolution centroid coordinates are published and available for additional analyses by others [26].

We must note that $\mathrm{E} 212 \mathrm{Q}$, being catalytically deficient and unable to processively hydrolyze cellulose exhibited the same binding times as the WT (Fig. 6). E212Q also had a short-lived binding population with a characteristic binding time of $\sim 15 \mathrm{~s}$ and an 'immobilized' population on cellulose. Moreover, as already discussed, the catalytic domains of these two enzymes also exhibited the $\sim 15 \mathrm{~s}$ characteristic residence time. One could take the common residence times of the Cel7A variants to posit that dissociation of Cel7A is limited by the disengagement of its catalytic domain from the complexed cellodextrin. Decomplexation of Cel7A requires 'dethreading' of the cellodextrin chain from the active site tunnel, requiring the extraction of $\sim 8$ glucose residues forming the equivalent number of interactions in the tunnel [28]. Our data certainly suggest that dissociation is not limited by hydrolytic activity. Thus, we return to the conclusion that while it is possible that Cel7A is active throughout its residence on cellulose, it certainly does not have to be.

\section{Additional evidence for Cel7A activity in the single-molecule imaging experiments}

In two separate instances during the course of observing enzyme binding to cellulose, fibrils with associated enzymes were seen to kink along the lengths (frames-671-673 in Fig. 9a-c and Additional file 11; frames 234-236 in Additional file 12). Earlier works have shown that as Cel7A hydrolyze cellulose, the microstructure undergoes structural changes such as fibrillation and segmentation [38, 39]. Moreover, computational modeling based on transmission electron microscopy revealed that cellulose microfibrils kink along their lengths in their energy minimized state [40]. Ciesielski et al. proposed that highly crystalline cellulose fibrils kink to release internal stresses [41]; we speculate that we observed this stress release due to the cellulose fibrils being actively hydrolyzed. Although the process of kinking was only observed twice, kinked fibrils were frequently observed in the experimental samples.

\section{Conclusions}

We have measured the binding lifetimes of Cel7 A, its catalytically deficient mutant, E212Q, and their respective catalytic domains on cellulose. All the Cel7A variants bind non-specifically to hydrophobized glass, even when passivated by BSA; non-specific binding, however, is highly dynamic with characteristic binding times $<10 \mathrm{~s}$. All the Cel7A variants were more specific and had stronger affinity to cellulose than to the hydrophobized glass, regardless of whether the variant had a CBM and linker. The lack of CBM and linker, however, manifested clearly as reduced concentration of the enzyme bound to cellulose. From our observations, we speculate that the CBM and linker increases the affinity of Cel7A to cellulose possibly by facilitating recognition of complexation sites and by aiding in the uptake of a cellodextrin chain into the enzyme active site. The increase in the affinity of the intact Cel7A due to the CBM and linker also appeared to come at the cost of increasing the fraction of immobilized enzymes on cellulose. Removing the CBM and linker resulted in a fraction of the long-lived bound Cel7A catalytic domain population to dissociate within $\sim 100 \mathrm{~s}$. The wild-type and catalyticdeficient Cel7A catalytic domains exhibited similar binding behavior on cellulose, thus supporting that residence time (or conversely dissociation rates) of Cel7A from cellulose is not catalysis limited. The crystalline cellulose fibrils used in this study were highly polished to reduce the number of productive Cel7A binding sites. Consequently, the cellulose surface coverage of bound Cel7A was vastly reduced. Binding behavior between intact and truncated core versions of Cel7A was similar. Taken together, we conclude that the Cel7A-cellulose interactions measured in our study were primarily bound by the catalytic domain. The cellulosebinding module facilitates the catalytic domain, but does not appear to be the driver for interactions of Cel7A at the interface of cellulose.

\section{Methods}

\section{Cellulose preparation}

Algal cellulose (AC) was purified from Cladophora aegagropila by sequential and repeated alkali and acidified hypochlorite treatments as described previously [23, 42]. Isolated algal cellulose fibrils were further treated with $5 \mathrm{M}$ hydrochloric acid at $70{ }^{\circ} \mathrm{C}$ overnight [13]. The 

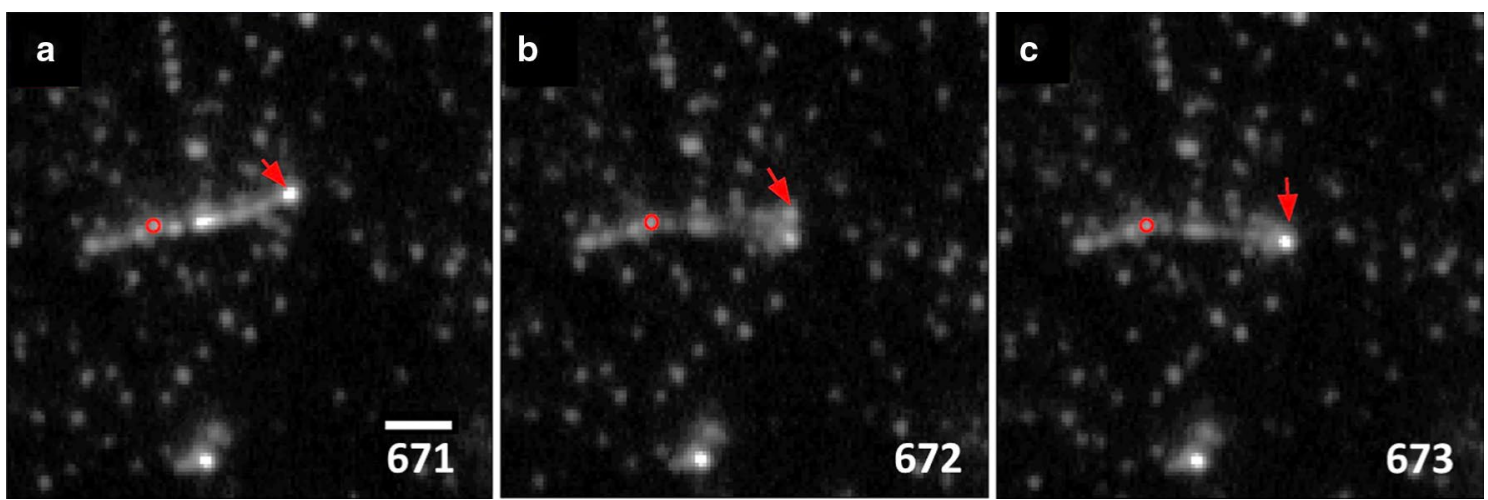

Fig. 9 Three successive frames (1 frame/s) (a-c) that capture formation of a kink in an algal cellulose fibril treated with WT core. Red arrows point to the fibril tips while the red circle shows the pivot point about which the fibril kinks. Frame numbers are shown in each panel. Video sequence for this and a second observation are shown in Additional files 11 and 12. Scale bar indicates $2 \mu \mathrm{m}$

residual AC fibrils were washed thoroughly with water to remove excess acid, then stored at $4{ }^{\circ} \mathrm{C}$ with $0.02 \%$ sodium azide until further use. The productive Cel7A binding capacity of the $\mathrm{AC}$ was determined from initial cellobiose production rates at saturating conditions as previously described $[13,23]$.

\section{Enzyme preparation}

Trichoderma reesei Cel7A ( $\left.\mathrm{WT}_{\text {intact }}\right)$ was purified from a commercial Trichoderma reesei cellulase preparation (Sigma Aldrich Catalog number C2720) as previously described [39, 43].

The E212Q gene was constructed with the pGEM$T$ easy vector (Promega Corporation, WI, USA) and transformed into Escherichia coli $\mathrm{DH} 5 \alpha+\mathrm{Amp}^{+}$. The gene was extracted and ligated to the $\mathrm{p} \operatorname{TrEno}$ vector with the eno promoter [44]. The $p$ TrEno/E212Q vector, containing eno promoter and an E212Q fragment, was transformed into the T. reesei strain AST1116 via electroporation [45]. The $p$ Treno plasmid expressed the E212Q in T. reesei in glucose-rich media without contamination from the CBHI wild-type. The transformed T. reesei AST1116 was spread onto potato-dextrose agar plates with hygromycin B as a selection marker at $30{ }^{\circ} \mathrm{C}$ until the sporulating lawn was observed. The colonies from the sporulating lawns were transferred to Mandels and Andreotti Medium (MA) with $1 \mathrm{M}$ glucose and hygromycin $\mathrm{B}$ at $30^{\circ} \mathrm{C}$ with $200 \mathrm{rpm}$ and incubated for 3 days. The E212Q enzyme $\left(E 212 Q_{\text {intact }}\right)$ was purified by fast protein liquid chromatography (FPLC) through a multistep process, the details of which can be found elsewhere [45]. Briefly, the protein was isolated using hydrophobic interaction chromatography followed by anion exchange chromatography using a
Resource Q column, a second round of hydrophobic interaction chromatography using a Resource ISO column and finally size exclusion chromatography. The purified product was confirmed as E212Q by Western blot analysis and protein sequencing [45]. The loss of cellulolytic activity of E212Q compared to the wild-type Cel7A was confirmed on the recalcitrant algal cellulose and highly digestible phosphoric acid swollen cellulose (Additional file 1: S1).

Isolated catalytic domains of Cel7A and E212Q

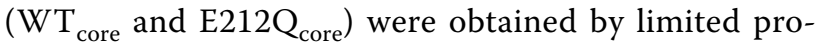
teolysis of the purified Cel7A (WT $\mathrm{T}_{\text {intact }}$ ) and $\mathrm{E} 212 \mathrm{Q}$ $\left(\mathrm{E} 212 \mathrm{Q}_{\text {intact }}\right)[11,46] . \mathrm{WT}_{\text {intact }}$ or $\mathrm{E} 212 \mathrm{Q}_{\text {intact }}$ was incubated with immobilized papain (Thermo Fisher Scientific, cat\# 20341), equilibrated in the digestion buffer (20 $\mathrm{mM}$ sodium phosphate, $10 \mathrm{mM}$ ethylenediamine tetraacetic acid, $20 \mathrm{mM}$ cysteine $\mathrm{HCl}$ ) for $7 \mathrm{~h}$ at $37{ }^{\circ} \mathrm{C}$ and gentle agitation. The supernatant containing the cleaved fractions were separated from the papain by centrifugation, then concentrated and separated by size exclusion chromatography (Superdex 200, GE healthcare) in $5 \mathrm{mM} \mathrm{NaOAc}$ and $100 \mathrm{mM} \mathrm{NaCl}, \mathrm{pH}$. The fractions containing the isolated catalytic domain as confirmed by SDS PAGE (Fig. 10) were pooled, concentrated, and stored for further use.

All enzymes were labeled with Cy5 fluorophore (GE Healthcare Life Sciences, Amersham) per manufacturer procedures and separated from excess dye using Zeba Desalting columns (Thermo Fisher Scientific) as previously described [17]. This procedure resulted in a degree of labeling (moles of Cy $5 /$ mole protein) of 0.71 and 0.25 for $\mathrm{WT}_{\text {intact }}$ and $\mathrm{WT}_{\text {core }}$, respectively, and 0.63 and 0.79 for $\mathrm{E}_{212 \mathrm{Q}_{\text {intact }}}$ and $\mathrm{E} 212 \mathrm{Q}_{\text {core }}$, respectively. 


\section{Cellulose deposition on glass coverslips}

Never-dried cellulose was deposited onto hydrophobically silanized glass coverslips by gravity-aided settling in the imaging channels. Imaging channels of $10 \mu \mathrm{L}$ working volume were built onto the hydrophobized glass coverslips as described previously [17]. The channels were filled with cellulose suspensions $(0.025-0.25 \mathrm{mg} / \mathrm{mL})$, sealed, and allowed to settle until ready for use (minimum settling time was overnight in the refrigerator). Prior to use, unbound cellulose was rinsed off the surface with buffer and the channels were incubated with $10 \mathrm{mg} /$ $\mathrm{ml}$ of bovine serum albumin (BSA) for $>10 \mathrm{~min}$ to passivate the surface. Successful deposition of cellulose fibrils onto the imaging surfaces was confirmed by AFM or by staining with pontamine fast scarlet $4 \mathrm{~B}$ (PFS), a cellulosespecific fluorescent dye [47].

\section{Atomic force microscopy (AFM) imaging of cellulose}

Imaging of cellulose adhered on hydrophobic glass coverslips was done in tapping mode in water using a MFP 3D Bio AFM (Asylum Research) with silicon AFM probes (AC240 TS, Asylum Research) as described earlier [39]. Scanning parameters were optimized for each acquisition. The images were processed using the Asylum Research MFP 3D template in Igor Pro (Wavemetrics, Inc.).

\section{Single-molecule fluorescence imaging}

A through-objective total internal reflection excitation fluorescence microscopy (TIRFM) setup was used to collect single-molecule fluorescence images of individual Cy5-labeled enzyme molecules bound to cellulose fibrils. A detailed description of this setup is given elsewhere [48]. Briefly, $488 \mathrm{~nm}$ and $637 \mathrm{~nm}$ excitation laser beams were reflected by a multiline dichroic mirror (FF500/646Di01, Semrock) and focused at the back aperture of a 1.49 NA $60 \times$ oil-immersion objective (Olympus) to provide total internal reflection (TIR) excitation at the cover glass/water interface across a $\sim 50 \mu \mathrm{m}$ diameter area in the object plane (Fig. 1a). Sample emission was collected and imaged by the same objective onto the $512 \times 512$-pixel sensor of an electron multiplying CCD (EMCCD) camera (Photonmax, Princeton Instruments). A 37-nm-wide bandpass filter centered at $676 \mathrm{~nm}$ was used to isolate Cy5 fluorescence excited at $637 \mathrm{~nm}$. A $40 \mathrm{~nm}$ wide bandpass filter centered at $562 \mathrm{~nm}$ was used to isolate pontamine fast scarlet $4 \mathrm{~B}$ (PFS) fluorescence excited at $488 \mathrm{~nm}$. An image of Cy5-labeled Cel7A bound to cellulose collected in a field of view of $56 \times 56 \mu \mathrm{m}^{2}$ is shown in (Fig. 1b). For the binding time measurements, the overall magnification of the imaging system $(73 \times)$ mapped each EMCCD pixel to a $220 \times 220 \mathrm{~nm}$ area in the object plane. Moreover, relatively low power $(\sim 0.2 \mathrm{~mW}$ (a) $637 \mathrm{~nm}$ ) excitation was used to reduce the effect of Cy5 photobleaching on the binding time measurements. Image stacks were collected at EMCCD camera integration times of $1 \mathrm{~s}$.

In a typical experiment, the Cy5-labeled enzymes in an oxygen-scavenging buffer at a concentration of 50-100 pM were loaded into the $10-\mu \mathrm{L}$ channel and imaged over the course of 40-50 min at 1 frame per second to generate movies consisting of a series of sequential images (image stacks). The oxygen-scavenging buffer (glucose oxidase, catalase, $2 \%$ glucose and trolox in $50 \mathrm{mM}$ sodium acetate buffer $\mathrm{pH}$ 5) was used to enhance Cy5 photostability and reduce fluorophore blinking [49]. Under the imaging conditions used in this study, immobilized Cy5 fluorophores exhibited two decay lifetimes of $195 \mathrm{~s}$ and $1100 \mathrm{~s}$ when illuminated in buffer with the oxygen-scavenging system. When the oxygen-scavenging buffer was not used, Cy5 decay lifetimes were $5 \mathrm{~s}$ and $20 \mathrm{~s}$ (see Figure S2 in Additional file 1). Compressed videos of the data used in this study are provided as Additional

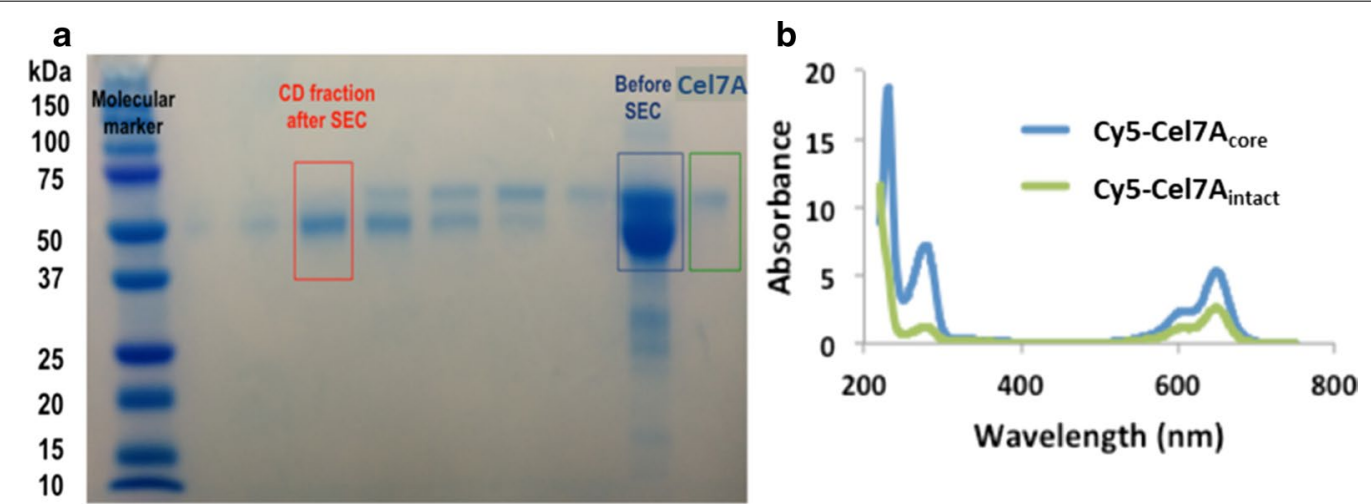

Fig. 10 a SDS PAGE showing the different bands before and after size exclusion chromatography. $\mathbf{b}$ Absorbance spectra of Cy5-labeled WT intact and $W T_{\text {core }}$ enzymes 
files $2,3,4,5,6,7,8,9,10,11,12$ while the raw data are published and available elsewhere [26].

\section{Single-molecule image analysis to obtain enzyme-binding lifetimes}

The image stacks were processed using Image J software (Version 1.49, NIH). The position coordinates of individual enzyme molecules adhered to cellulose in the image stacks were determined using DAOSTORM, a single-molecule fluorescence localization algorithm that was adapted from the astronomy software package DAOPHOT [22]. Detailed information about preparation of the raw datasets for analysis can be found in Additional file 1: S3. The output from DAOSTORM, a list of spot centroid $x-y$ coordinates and fluorescence intensities of the individual localized enzyme molecules, was corrected for lateral drift of the microscope stage and analyzed with a custom algorithm developed in-house to count the number of frames during which individual enzyme molecules were present at given locations $(x, y)$. The reconstructed super-resolution images generated from the DAOSTORM output were used to mask images to isolate binding time analyses on regions with (e.g., Fig. 4) or without fibrils. These data were used to compile binding time histograms that were fit to multiple exponential decay models using the differential evolution (genetic optimization) algorithm [50]. Enzymes found in the first and last frames of the image stack were not included as their total residence times could not be determined. The fits were minimized using Poisson deviance [51] as the cost function, implemented in Igor Pro (Wavemetrics, Version 6.34A) to determine characteristic binding times. The best fit was chosen based on the residual plots and reduced Poisson deviance value close to 1 to optimally fit the data (details on binding time analyses are provided in Additional file 1: S4 and S5).

A two-sample $t$ test was used to determine significant differences between characteristic lifetimes of the binding populations. Separate statistical tests were conducted

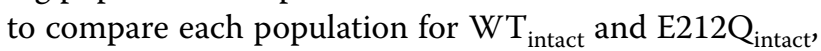
$\mathrm{WT}_{\text {core }}$ and $\mathrm{E} 212 \mathrm{Q}_{\text {core }}$.

\section{Supplementary information}

Supplementary information accompanies this paper at https://doi. org/10.1186/s13068-020-1649-7.

Additional file 1: S1. Relative activities of Cel7A and E212Q used in this study. S2. Photostability of Cy5 labels under imaging conditions used in this study. S3. Localization of individual enzymes in a single-molecule (SM) fluorescence image sequence using DAOSTORM. S4. Obtaining Binding lifetimes of individual enzyme molecules using output from DAOSTORM. S5. Multi-exponential fitting of the binding time histograms. S6. Binding of Cel7A and Cel7A CD on phosphoric acid swollen cellulose
(PASC). S7. Automating the analysis of single-molecule (SM) image stacks for unbiased determination of binding lifetimes of cellulases on cellulose.

Additional file 2: Cy5-labeled $\mathrm{WT}_{\text {intact }}$ in oxygen scavenging buffer with $\mathrm{HCl}$ treated algal cellulose fibrils. Data collected at 1 frame per second (fps). Playback at $20 \mathrm{fps} .56 \mu \mathrm{m} \times 56 \mu \mathrm{m}$. (TrCel7A111130.spe).

Additional file 3: Cy5-labeled WT $\mathrm{W}_{\text {core }}$ in oxygen scavenging buffer with $\mathrm{HCl}$ treated algal cellulose fibrils. Data collected at 1 frame per second (fps). Playback at $20 \mathrm{fps} .66 \mu \mathrm{m} \times 66 \mu \mathrm{m}$. (Cel7ACD123032.spe).

Additional file 4: Cy5-labeled WT $\mathrm{T}_{\text {core }}$ in oxygen scavenging buffer with $\mathrm{HCl}$ treated algal cellulose fibrils. Data collected at 1 frame per second (fps). Playback at 20 fps. $66 \mu \mathrm{m} \times 66 \mu \mathrm{m}$. (Cel7ACD133451.spe).

Additional file 5: Cy5-labeled WT $\mathrm{T}_{\text {core }}$ in oxygen scavenging buffer with $\mathrm{HCl}$ treated algal cellulose fibrils. Data collected at 1 frame per second (fps). Playback at $20 \mathrm{fps} .66 \mu \mathrm{m} \times 66 \mu \mathrm{m}$. (Cel7ACD143742.spe).

Additional file 6: Cy5-labeled E212Q $\mathrm{Q}_{\text {intact }}$ in oxygen scavenging buffer with $\mathrm{HCl}$ treated algal cellulose fibrils. Data collected at 1 frame per second (fps). Playback at $20 \mathrm{fps} .66 \mu \mathrm{m} \times 66 \mu \mathrm{m}$. (E212Q160828).

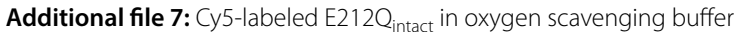
with $\mathrm{HCl}$ treated algal cellulose fibrils. Data collected at 1 frame per second (fps). Playback at $20 \mathrm{fps} .66 \mu \mathrm{m} \times 66 \mu \mathrm{m}$. (E212Q170336).

Additional file 8: Cy5-labeled $\mathrm{E} 212 \mathrm{Q}_{\text {core }}$ in oxygen scavenging buffer with $\mathrm{HCl}$ treated algal cellulose fibrils. Data collected at 1 frame per second (fps). Playback at $20 \mathrm{fps} .66 \mu \mathrm{m} \times 66 \mu \mathrm{m}$. (E212QCD181309.spe).

Additional file 9: Cy5-labeled $\mathrm{E} 212 \mathrm{Q}_{\text {core }}$ in oxygen scavenging buffer with $\mathrm{HCl}$ treated algal cellulose fibrils. Data collected at 1 frame per second (fps). Playback at $20 \mathrm{fps} .66 \mu \mathrm{m} \times 66 \mu \mathrm{m}$. (E212QCD190922.spe).

Additional file 10: One example of lateral translation of Cy5-labeled $W T_{\text {core }}$ along a cellulose fibril. Data collected at $1 \mathrm{fps}$, playback at $20 \mathrm{fps}$.

Additional file 11: Movement of the tip of an algal cellulose fibril treated with WT in $50 \mathrm{mM}$ sodium acetate buffer, $\mathrm{pH}$ 5. The movement of the fibril tip can be observed between frames 671-673 shown by the red arrow. Data collected at 1 frame per second (fps). Playback at $10 \mathrm{fps}$, elapsed time $749 \mathrm{~s}$. Scale bar is $2 \mu \mathrm{m}$.

Additional file 12: Movement of a fibril tip of algal cellulose treated with $\mathrm{WT}_{\text {core }}$ in $50 \mathrm{mM}$ sodium acetate buffer, $\mathrm{pH}$ 5. The movement of the fibril tip can be observed between frames 234-236 shown by the red arrow. Data collected at $1 \mathrm{fps}$. Playback at $10 \mathrm{fps}$, elapsed time, $306 \mathrm{~s}$. Scale bar is $1 \mu \mathrm{m}$.

\section{Abbreviations}

TIRFM: total internal reflection fluorescence microscopy; AFM: atomic force microscopy; AC: algal cellulose; PASC: phosphoric acid swollen cellulose; Cel7A: Trichoderma reesei Cel7A.

\section{Acknowledgements}

This work (LA-UR-19-28848) was performed, in part, at the Center for Integrated Nanotechnologies, an Office of Science User Facility operated for the U.S. Department of Energy (DOE) Office of Science. Los Alamos National Laboratory, an affirmative action equal opportunity employer, is managed by Triad National Security, LLC for the U.S. Department of Energy's NNSA, under contract 89233218CNA000001. The authors acknowledge Dr. Jeff Linger and Dr. Steve Decker from the National Renewable Energy Laboratory (NREL) for their help in cloning and expressing the E212Q mutant, and Dr. Benedikt Blossom for helpful discussions.

\section{Authors' contributions}

ARM conducted the overall study and wrote the first draft; PMG led the singlemolecule imaging experiments; RUR developed the binding time analysis algorithm; NK cloned, purified and characterized E212Q; AH produced, characterized and imaged the algal cellulose; JN characterized the productive binding capacity of the substrates and contributed to the discussion; TJ conceived the study, supervised all aspects of the work and manuscript preparation. All authors contributed to editing the manuscript. All authors read and approved the final manuscript. 


\section{Funding}

This project was supported in part by the National Science Foundation (NSF) Engineering directorate-CBET Grant No. 1055518.

\section{Availability of data and materials}

Additional data and compressed videos of the TIRFM image sequences supporting the conclusions of the article are included within the article and its additional files. Additionally, the datasets supporting the conclusions of this article are available in the University of California Dash data repository https ://doi.org/10.25338/B8ZC80 [26]. Filenames of the published original raw data are given in the figure captions.

\section{Ethics approval and consent to participate}

Not applicable.

\section{Consent for publication}

Not applicable.

\section{Competing interests}

The authors declare that they have no competing interests.

\section{Author details}

${ }^{1}$ Biological and Agricultural Engineering, University of California, Davis, One Shields Ave., Davis, CA 95616, USA. ${ }^{2}$ Center for Integrated Nanotechnologies, Los Alamos National Laboratory, Los Alamos, NM 87545, USA. ${ }^{3}$ Gracenote, Inc., 2000 Powell Street, Suite 1500, Emeryville, CA 94608, USA. ${ }^{4}$ Biotechnology, Faculty of Engineering and Industrial Technology, Silpakorn University, Nakhon Pathom 73000, Thailand. ${ }^{5}$ Chemical Engineering, University of California, Davis, One Shields Ave., Davis, CA 95616, USA. ${ }^{6}$ Molecular Biophysics and Integrated Bioimaging, Lawrence Berkeley National Lab, 1 Cyclotron Road, Berkeley, CA 94720, USA.

Received: 12 September 2019 Accepted: 2 January 2020 Published online: 18 January 2020

\section{References}

1. Wagner L, Ross I, Foster J, Hankamer B. Trading off global fuel supply, $\mathrm{CO}_{2}$ emissions and sustainable development. PLOS ONE. 2016;11(3):e0149406.

2. Hill J, Polasky S, Nelson E, Tilman D, Huo H, Ludwig L, et al. Climate change and health costs of air emissions from biofuels and gasoline. Proc Natl Acad Sci. 2009;106(6):2077.

3. Nishiyama Y. Structure and properties of the cellulose microfibril. J Wood Sci. 2009;55(4):241-9.

4. Payne CM, Knott BC, Mayes HB, Hansson H, Himmel ME, Sandgren M, et al. Fungal cellulases. Chem Rev. 2015;115(3):1308-448.

5. Müller G, Várnai A, Johansen KS, Eijsink VGH, Horn SJ. Harnessing the potential of LPMO-containing cellulase cocktails poses new demands on processing conditions. Biotechnol Biofuels. 2015;8(1):187.

6. Jeoh T, Cardona MJ, Karuna N, Mudinoor AR, Nill J. Mechanistic kinetic models of enzymatic cellulose hydrolysis—a review. Biotechnol Bioeng. 2017;114(7):1363-631.

7. Cruys-Bagger N, Alasepp K, Andersen M, Ottesen J, Borch K, Westh P. Rate of threading a cellulose chain into the binding tunnel of a cellulase. J Phys Chem B. 2016;120(25):5591-600.

8. Hilden $L$, Johansson $G$. Recent developments on cellulases and carbohydrate-binding modules with cellulose affinity. Biotechnol Lett. 2004;26(22):1683-93.

9. Linder M, Teeri TT. The roles and function of cellulose-binding domains. J Bacteriol. 1997;57:15-28.

10. Payne CM, Resch MG, Chen L, Crowley MF, Himmel ME, Taylor LE, et al. Glycosylated linkers in multimodular lignocellulose-degrading enzymes dynamically bind to cellulose. Proc Natl Acad Sci. 2013;110(36):14646-51.

11. Tomme P, Vantilbeurgh $H$, Pettersson G, Vandamme J, Vandekerckhove J, Knowles J, et al. Studies of the cellulolytic system of Trichoderma reesei Qm-9414-analysis of domain function in 2 cellobiohydrolases by limited proteolysis. Eur J Biochem. 1988;170(3):575-81.
12. Igarashi K, Uchihashi T, Koivula A, Wada M, Kimura S, Okamoto T, et al. Traffic jams reduce hydrolytic efficiency of cellulase on cellulose surface. Science. 2011;333:1279-82

13. Nill J, Jeoh T. The role of evolving interfacial substrate properties on heterogeneous cellulose hydrolysis kinetics. bioRxiv. 2019;69:1071.

14. Nill JE, Karuna N, Jeoh T. The impact of kinetic parameters on cellulose hydrolysis rates. Process Biochem. 2018;74:108-17.

15. Cruys-Bagger N, Elmerdahl J, Praestgaard E, Tatsumi H, Spodsberg N, Borch $\mathrm{K}$, et al. Pre-steady-state kinetics for hydrolysis of insoluble cellulose by cellobiohydrolase Cel7A. J Biol Chem. 2012;287(22):18451-8.

16. Kurasin M, Valjamae P. Processivity of cellobiohydrolases is limited by the substrate. J Biol Chem. 2011;286(1):169-77.

17. Jung J, Sethi A, Gaiotto T, Han JJ, Jeoh T, Gnanakaran S, et al. Binding and movement of individual Cel7A cellobiohydrolases on crystalline cellulose surfaces revealed by single-molecule fluorescence imaging. J Biol Chem. 2013;288(33):24164-72

18. Nakamura A, Tasaki T, Ishiwata D, Yamamoto M, Okuni Y, Visootsat A, et al. Single-molecule imaging analysis of binding, processive movement, and dissociation of cellobiohydrolase Trichoderma reesei Cel6A and its domains on crystalline cellulose. J Biol Chem. 2016;291(43):22404-13.

19. Shibafuji Y, Nakamura A, Uchihashi T, Sugimoto N, Fukuda S, Watanabe $\mathrm{H}$, et al. Single-molecule imaging analysis of elementary reaction steps of Trichoderma reesei cellobiohydrolase I (Cel7A) hydrolyzing crystalline cellulose la and IIII. J Biol Chem. 2014;289(20):14056-65.

20. Knott BC, Haddad Momeni M, Crowley MF, Mackenzie LF, Götz AW, Sandgren $M$, et al. The mechanism of cellulose hydrolysis by a two-step, retaining cellobiohydrolase elucidated by structural and transition path sampling studies. J Am Chem Soc. 2014;136(1):321-9.

21. Stahlberg J, Johansson G, Petterson G. A new model for enzymatic hydrolysis of cellulose based on the two-domain structure of cellobiohydrolase I. Bio/Technology. 1991;9:286-90.

22. Holden SJ, Uphoff S, Kapanidis AN. DAOSTORM: an algorithm for highdensity super-resolution microscopy. Nat Meth. 2011;8(4):279-80.

23. Karuna $\mathrm{N}$, Jeoh $\mathrm{T}$. The productive cellulase binding capacity of cellulosic substrates. Biotechnol Bioeng. 2017;114(3):533-42.

24. Mudinoor AR. Surface interactions of Trichoderma reesei Cel7A and its variants on cellulose. Davis: University of California; 2018.

25. Igarashi K, Koivula A, Wada M, Kimura S, Penttilä M, Samejima M. High speed atomic force microscopy visualizes processive movement of Trichoderma reesei cellobiohydrolase I on crystalline cellulose. J Biol Chem. 2009;284(52):36186-90

26. Jeoh T, Goodwin PM, Mudinoor AR. Single-molecule image sequences of Trichoderma reesei Cel7A and variants on cellulose fibrils. UC Davis. 2020;1:1. https://doi.org/10.25338/B8ZC80.

27. Divne C, Stahlberg J, Reinikainen T, Ruohonen L, Pettersson G, Knowles JKC, et al. The 3-dimensional crystal-structure of the catalytic core of cellobiohydrolase-I from Trichoderma reesei. Science. 1994;265(5171):524-8.

28. Divne C, Stahlberg J, Teeri TT, Jones A. High-resolution crystal structures reveal how a cellulose chain is bound in the 50 angstrom long tunnel of cellobiohydrolase I from Trichoderma reesei. J Mol Biol. 1998;275:309-25.

29. Kari J, Olsen J, Borch K, Cruys-Bagger N, Jensen K, Westh P. Kinetics of cellobiohydrolase (Cel7A) variants with lowered substrate affinity. J Biol Chem. 2014;289(47):32459-68.

30. Srisodsuk M, Reinikainen T, Penttila M, Teeri TT. Role of the interdomain linker peptide of Trichoderma reesei cellobiohydrolase I in its interaction with crystalline cellulose. J Biol Chem. 1993;268(28):20756-61.

31. Badino SF. Enzymatic Hydrolysis of Cellulose. Roskilde Universitet; 2018. https://rucforsk.ruc.dk/ws/files/63247300/Phd_Silke_Flindt_Badino.pdf.

32. Cruys-Bagger N, Tatsumi H, Ren GR, Borch K, Westh P. Transient kinetics and rate-limiting steps for the processive cellobiohydrolase Cel7A: effects of substrate structure and carbohydrate binding domain. Biochemistry. 2013;52(49):8938-48.

33. Kari J, Andersen M, Borch K, Westh P. An inverse Michaelis-Menten approach for interfacial enzyme kinetics. ACS Catal. 2017;7(7):4904-14.

34. Kont R, Kari J, Borch K, Westh P, Väljamäe P. Inter-domain synergism is required for efficient feeding of cellulose chain into active site of cellobiohydrolase Cel7A. J Biol Chem. 2016;291(50):26013-23. 
35. Bu LT, Beckham GT, Crowley MF, Chang CH, Matthews JF, Bomble YJ, et al. The energy landscape for the interaction of the family 1 carbohydratebinding module and the cellulose surface is altered by hydrolyzed glycosidic bonds. J Phys Chem B. 2009;113(31):10994-1002.

36. Kari J, Olsen JP, Jensen K, Badino SF, Krogh KBRM, Borch K, et al. Sabatier principle for interfacial (heterogeneous) enzyme catalysis. ACS Catal. 2018;8(12):11966-72.

37. Beckham GT, Matthews JF, Bomble YJ, Bu LT, Adney WS, Himmel ME, et al. Identification of amino acids responsible for processivity in a family 1 carbohydrate-binding module from a fungal cellulase. J Phys Chem B. 2010;114(3):1447-53.

38. Jeoh T, Santa-Maria MC, O'Dell PJ. Assessing cellulose microfibrillar structure changes due to cellulase action. Carbohydr Polym. 2013;97(2):581-6.

39. Santa-Maria M, Jeoh T. Molecular-scale investigations of cellulose microstructure during enzymatic hydrolysis. Biomacromol. 2010;11(8):2000-7.

40. Ciesielski PN, Matthews JF, Tucker MP, Beckham GT, Crowley MF, Himmel $\mathrm{ME}$, et al. 3D electron tomography of pretreated biomass informs atomic modeling of cellulose microfibrils. ACS Nano. 2013;7(9):8011-9.

41. Ciesielski PN, Wagner R, Bharadwaj VS, Killgore J, Mittal A, Beckham GT, et al. Nanomechanics of cellulose deformation reveal molecular defects that facilitate natural deconstruction. Proc Natl Acad Sci. 2019;29:201900161.

42. O'Dell PJ, Mudinoor AR, Parikh SJ, Jeoh T. The effect of fibril length and architecture on the accessibility of reducing ends of cellulose la to Trichoderma reesei Cel7A. Cellulose. 2015;22(3):1697-713.

43. Jeoh T, Ishizawa C, Davis MF, Himmel ME, Adney WS, Johnson DK. Cellulase digestibility of pretreated biomass is limited by cellulose accessibility. Biotechnol Bioeng. 2007;98(1):112-22.

44. Li J, Wang J, Wang S, Xing M, Yu S, Liu G. Achieving efficient protein expression in Trichoderma reesei by using strong constitutive promoters. Microb Cell Factor. 2012;11(1):84
45. Linger JG, Taylor LE, Baker JO, Vander Wall T, Hobdey SE, Podkaminer K, et al. A constitutive expression system for glycosyl hydrolase family 7 cellobiohydrolases in Hypocrea jecorina. Biotechnol Biofuels. 2015;8:12.

46. Van Tilbeurgh H, Tomme P, Claeyssens M, Bhikhabhai R, Petterson G. Limited proteolysis of the cellobiohydrolase I from Trichoderma reesei. FEBS. 1986;20(2):223-7.

47. Anderson CT, Carroll A, Akhmetova L, Somerville C. Real-time imaging of cellulose reorientation during cell wall expansion in arabidopsis roots. Plant Physiol. 2010;152(2):787-96.

48. Han JJ, Kunde YA, Hong-Geller E, Werner JH. Actin restructuring during Salmonella typhimurium infection investigated by confocal and superresolution microscopy. J Biomed Opt. 2014;19(1):016011.

49. Aitken CE, Marshall RA, Puglisi JD. An oxygen scavenging system for improvement of dye stability in single-molecule fluorescence experiments. Biophys J. 2008;94(5):1826-35.

50. Bowen DK, Tanner BK, Wormington M, Panaccione C, Matney KM, Bowen DK. Characterization of structures from $X$-ray scattering data using genetic algorithms. Philos Trans R Soc Lond Ser Math Phys Eng Sci. 1999;357(1761):2827-48.

51. Steinbach PJ. Filtering artifacts from lifetime distributions when maximizing entropy using a bootstrapped model. Anal Biochem. 2012;427(1):102-5.

\section{Publisher's Note}

Springer Nature remains neutral with regard to jurisdictional claims in published maps and institutional affiliations.
Ready to submit your research? Choose BMC and benefit from:

- fast, convenient online submission

- thorough peer review by experienced researchers in your field

- rapid publication on acceptance

- support for research data, including large and complex data types

- gold Open Access which fosters wider collaboration and increased citations

- maximum visibility for your research: over 100M website views per year

At BMC, research is always in progress.

Learn more biomedcentral.com/submissions 